American Journal of Applied Sciences 9 (1): 111-116, 2012

ISSN 1546-9239

(C) 2012 Science Publications

\title{
Power Quality Analysis in 6 MW Wind Turbine Using Static Synchronous Compensator
}

\author{
Valarmathi, R. and A. Chilambuchelvan \\ ${ }^{1}$ Department of ECE, Institute of Road and Transport Technology, Erode, TamilNadu, India \\ ${ }^{2}$ Department of E and I, RMD Engineering College, Chennai, TamilNadu, India
}

\begin{abstract}
Problem statement: An inherent problem with wind turbine power generation systems is the low power quality due to intermittent power generation in these systems. This not only affects the power generation but also the grid it is connected to. Approach: In this study a configuration consisting of a 6MW Wind Farm based on conventional Fixed Speed Induction Generator is analyzed. To improve the transient stability in the wind turbine generator a STATCOM is introduced in the system as an active voltage/var supporter. The impact of the introduced STATCOM and subsequent performance improvement in the power quality is studied. Results and Conclusion: The improved short-term voltage obtained when a STATCOM is introduced under various wind speed conditions is quantified. It is proved that STATCOM has a direct impact on reliability, however SVC needsto be studied due to their lower cost.
\end{abstract}

Key words: Wind energy, STATCOM, induction generator, power quality, power generation systems, Flexible Ac Transmission Systems (FACTS), Unified Power Flow Controller (UPFC), static synchronous compensator, electrical energy, wind turbine

\section{INTRODUCTION}

Wind power is a sustainable method to generate electrical energy by converting wind power to an alternate energy and in turn convert the same into electrical energy. Worldwide name plate capacity was pegged at $159.2 \mathrm{GW}$ and is increasing very fast. Currently $2 \%$ of the total energy generated and used comes from wind energy. Several countries have achieved good levels of wind power generation., such as $20 \%$ of stationary electricity production in Denmark, $14 \%$ in Ireland and Portugal, $11 \%$ in Spain and $8 \%$ in Germany in 2009. Over 80 countries around the world use wind energy on a commercial basis. Large scale wind farms are connected to the electrical transmission network with high efficiency. Large numbers of small wind energy generators are used to provide electricity to isolated locations. Advantages of wind energy is that it is available freely, clean and renewable. Wind is a continuously varying source of energy and so is the active power generated by the wind (Ramakumar et al., 1999). A major disadvantage of wind energy distribution systems connected to a weak grid is generation of flickers and harmonics thus reducing the quality of power.
With increase in penetration in the wind power, it has become necessary to address problems associated with maintaining a stable electric power system that may include different sources of energy including hydro, thermal, nuclear and solar (Ahilan et al., 2009). With the percentage of wind energy generated increasing; continuous connection of wind farms to the grid plays a crucial role in enabling uninterrupted power supply to the load, even in the case of minor disturbances. With wind farm capacity continuously being increased through the installation larger wind turbines, voltage stability and an efficient fault ride through capability are the key factors for successful penetration of wind energy in the electrical network. Grid codes require the wind energy generation system to provide continued uninterrupted operation under transient voltage conditions (Qiao and Harley, 2008). Wind power systems should meet these requirements for interconnection to the grid. Different grid code standards are set by different regulating bodies, but Nordic grid codes are becoming increasingly popular (Molinas et al., 2005). A major issue that needs to be addressed for interconnection of wind farms to the grid is its dynamic stability. The grid can collapse due to voltage instability occurring due to heavy loading conditions and the power system not able to meet the demands of reactive power.

Corresponding Author: R. Valarmathi, Department of ECE, Institute of Road and Transport Technology, Erode, TamilNadu, India 
Extensive modeling is required to study the effects of transients and stability of the wind energy system before implementation. Stand alone systems are more easier to model, analyze and control than larger power systems in simulation studies. A wind farm is usually spread over a wide area and has many wind generators which produce different amounts of power when they are exposed to different wind patterns. The generator used also plays a crucial role in the stability of the system. For example the operating characteristics of squirrel cage induction motor is that it consumes reactive power which is not a desired feature of the transmission system. In the case of a weak grid, the reactive power consumption of the generator is always fully compensated by capacitors. During a fault, the generator will accelerate due to the imbalance in the energy and electrical power delivered to the grid (Erkert, 2003). When the fault is cleared the voltage is not stabilized immediately and the generator continues to accelerate and consumes even larger amount of reactive power (Hossain et al., 2009). To overcome this problem active voltage regulators can be used.

Flexible Ac Transmission Systems (FACTS) are used extensively used in power systems because of their ability to provide flexible power control. Examples of such devices are the Static Synchronous Compensator (STATCOM) and the Unified Power Flow Controller (UPFC). STATCOM is preferred in wind farms due to its ability to provide bus bar voltage support either by supplying and/or absorbing reactive power in to the system (Srinivas and Devakumar, 2010).

In this study the performance of a wind farm with and without STATCOM is investigated. A $6 \mathrm{MW}$ wind farm is modelled and the output during fault conditions and the capability of STATCOM to compensate during the fault is studied. It is shown that transient and short term stability can also be achieved with the introduction of STATCOM in the system.

\section{MATERIALS AND METHODS}

Induction generators used in wind energy conversion systems: The major part of wind power generation is the induction generators. The different types of generators used are squirrel cage induction generators, wound rotor induction generators, permanent magnet and synchronous generators.

Squirrel cage induction generators: The squirrel cage induction generator is one of the widely generators due to its simplicity, very high reliability and low maintenance cost. These generators do not need slip rings and an excitation system. However the disadvantage is the need for a reactive power source to establish the rotating magnetic field. This problem is easily solved by the use of modern power electronics along with a single capacitor (Mittal et al., 2010; Toledo and Xie, 2005). Also these power electronic devices can inject power back into the network if needed. This type of generator is to be rotated above synchronous speed to generate power. With the use of the power electronic drive, the generator can also produce power at sub synchronous speeds. Figure 1 shows a squirrel cage induction generator coupled to a drive.

Wound rotor induction generators: Wound rotor induction generators are built such that the stator and rotor can give power simultaneously at certain speeds. Figure 2 shows this type of generator. The rotor is connected to the drive while the stator is connected to the grid terminals.

The magnetic field rotation speed is fixed in the stator winding as the stator is connected to the grid directly. The rotor side drive function is to adjust the rotation of the magnetic field in the rotor to match with that of the stator magnetic field. This is the operating principle of a synchronous generator where there is no slip between the stator and the rotor magnetic field. At sub synchronous speeds which can occur because of low wind, the drive will adjust the frequency fed to the rotor to make the rotor magnetic field seem like it is running faster at synchronous speed. This scenario requires drawing real power from the grid and the stator will add that power to the power from the turbine. In total, the wind system at this condition will be exporting power to the network. At super synchronous speeds which can occur due to high wind speed, the reverse action takes place. Here, the rotating magnetic field in the rotor will run in a direction opposite to the physical rotation of the rotor. The result is zero relative speed between the stator and rotor magnetic field. This way, both the stator and the rotor produce real power.

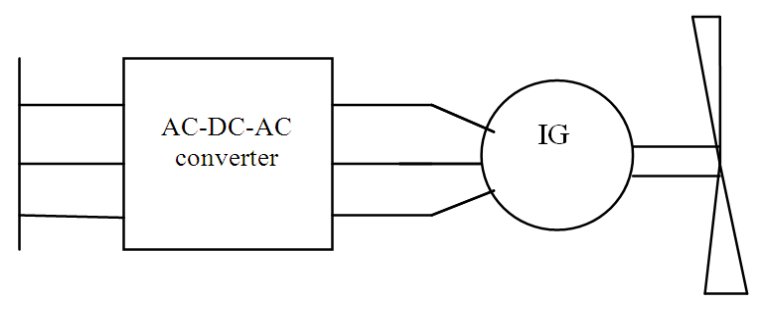

Fig. 1: Squirrel cage induction wind generator 112 


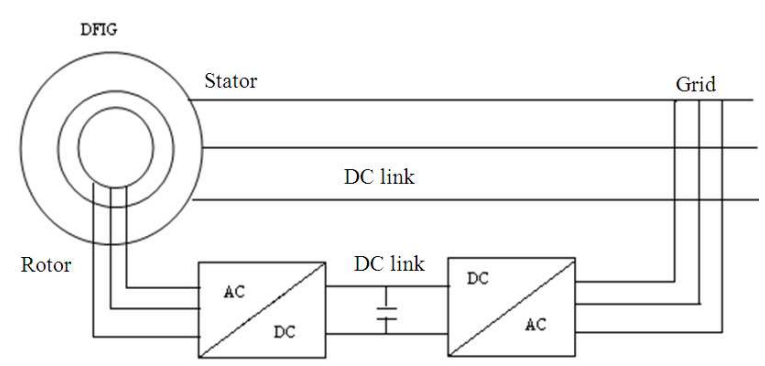

Fig. 2: Wound rotor induction generator

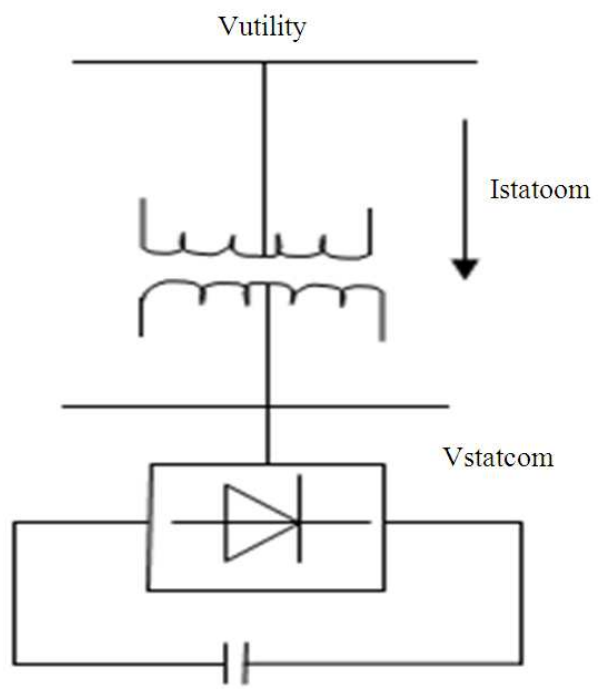

Fig. 3: Schematic diagram of STATCOM

Permanent magnet generator: Unlike the squirrel cage and wound rotor induction generators, the Permanent magnet generator does not need any external source to establish the rotor magnetic field as this is provided by the permanent magnets built into the generator. Without a drive, this generator will only produce power when the wind speed is high enough to attempt running the rotor at a speed higher than the stator magnetic field. The above process will increase the rotor speed and which in turn increases the power system frequency by a small fraction (Al-Majed and Fujigaki, 2010). When wind speed is too low the PMG will act as a motor consuming power from the network with a drive the Permanent magnet motor can produce power at a broad range of wind speeds. This is achieved by the drive making the network seem to run at a lower frequency during low wind speeds and the reverse takes place when the wind speed is high.

STATCOM: FACTS devices are commonly used in power systems to control the power flow control and for damping system oscillations. The other advantages of using FACTS are increased transmission line capacity and improved steady state voltage regulation. Use of FACTS also provides transient voltage support to avoid system collapse and damp power oscillations. The use of FACTS devices in wind power systems improves the transient and dynamic stability of the power system. One of the members of the family of the FACTS devices is the STATCOM that can be used effectively in wind farms to provide transient voltage support to prevent the system from being collapsed. STATCOM can also be considered to be an electronic generator of reactive power.

When power ' $\mathrm{S}$ ' $(\mathrm{P}+\mathrm{jQ})$ is transmitted over a power line with impedance ' $\mathrm{Z}$ ' $(\mathrm{R}+\mathrm{j} \mathrm{X})$, the resulting voltage drop $\Delta \mathrm{V}$ given by Eq. 1:

$\Delta=\frac{\mathrm{R} \cdot \mathrm{P}+\mathrm{X} \cdot \mathrm{Q}}{\mathrm{V}}$

In the case of large wind farms that are connected to transmission systems, the reactance $X \gg R$ and from Eq. $1, \Delta \mathrm{V}$ is directly proportional to the transferred reactive power $(\mathrm{Q})$. From Eq. 1, it is clear that an effective reactive power control strategy is required for efficient control of voltage. FACTS devices provide improved dynamic and steady state support. They also improve dynamic and transient stability, control dynamic over voltages and under voltages and also provide protection against voltage and frequency collapses.

A STATCOM is a shunt connected device that can provide reactive poer compensation and is capable of absorbing or generating reactive power. The STATCOM can be used to to control specific parameters of an electric power system. The STATCOM is a static compensator and is used to regulate voltage and to improve dynamic stability. A STATCOM supplies the required reactive power under various operating conditions, so that the network voltage can be controlled actively to improve the steady state stability of the network. The STATCOM has the advantage that it can be can be operated over its full output current range especially at very low voltage levels. The variation of the maximum VAR generated or absorbed by the STATCOM is linear with the utility or ac system voltage. Figure 3 and 4 shows the schematic diagram of the SVC and its V-I characteristics.

The system voltage of the fixed speed wind turbines can be enhanced by connecting capacitorsd because draw reactive power. The use of mechanically switched fixed shunt capacitors enhances the systems voltage stability limit, but they do not respond to voltage changes. 
Am. J. Applied Sci., 9 (1): 111-116, 2012

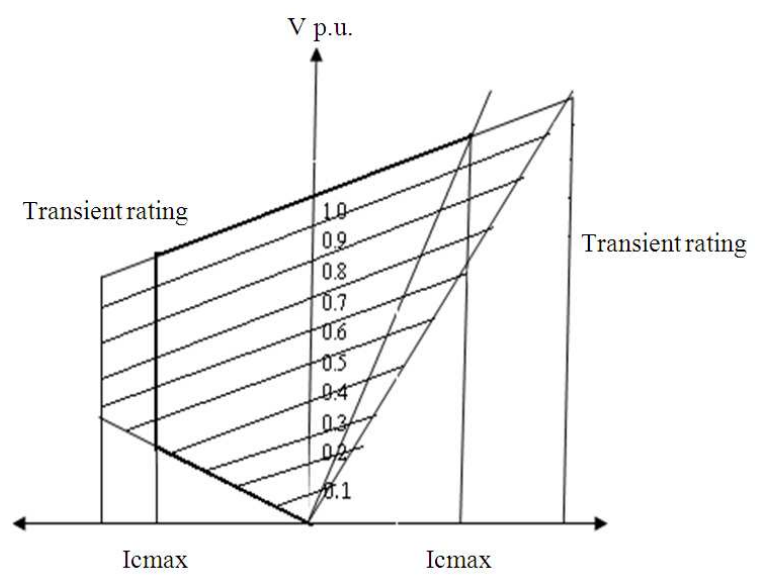

Fig. 4: Characteristics of STATCOM

Also, the voltage generated by the wind generators equipped with only fixed capacitors can exceed the voltage limit of 1.05.p.u. hence, a fiaxed capacitors cannot be used as the only source of reactive power compensation. In a STATCOM, the compensating current is not dependent on the voltage level at the connection point. So there is no decrease in the compensating current voltage drops. This is one of the most important advantages of STATCOM over a thyristorised SVC.

The output of the wind power plants and the total load varies throughout the day. Hence reactive power compensation is essential to maintain the normal voltage levels in the power system. The power system is seriously affected by reactive power imbalances. Such reactive power imbalances can be minimized by reactive power compensation devices such as STATCOM. The STATCOM can also compensate the low voltage ride through requirement is also compensated by using STATCOM because it can operate at full capacity even at low voltages.

\section{RESULTS AND DISCUSSION}

Experimental setup: In this study Matlab Simulink is used to create the experimental setup. The set up consists of two pairs of wind turbine each of $3 \mathrm{MW}$ capacity connected to a $25 \mathrm{kV}$ distribution system. The distribution system is connected to a $120 \mathrm{kV}$ grid located $10 \mathrm{~km}$ from the wind farm. The wind turbine uses squirrel cage induction generator with the stator winding connected directly to the gird and the rotor driven by a variable pitch wind turbine.
The pitch angle is the angle at which the blade surface contacts the wind. It is often variable to ensure optimum operation of the turbine in varying wind conditions and to prevent electrical overload and over speed in high winds. In the experimental setup, the pitch angle is controlled to limit the generator output power when the wind speed exceeds the nominal speed of $32 \mathrm{kmph}$. The Induction generator speed is set higher than the synchronous speed to generate power and the speed varies between $1.005 \mathrm{pu}$ at full load and at $1 \mathrm{pu}$ at no load.

Capacitor banks are used at each wind turbine low voltage bus to partly compensate reactive power absorbed by the induction generators. In the second setup a statcom of 3 Mvar is used to maintain the rest of the reactive power required to maintain the $25 \mathrm{kV}$ voltage close to $1 \mathrm{pu}$.

The wind turbine was designed as to yield the nominal mechanical power of $3 \mathrm{MW}$ at 32.4 $\mathrm{kmph}$.wind speed. Both the wind turbine and statcom models (used from matlab libraries) are phasor models. In the experimental setup with each simulation running for $20 \mathrm{sec}$, the initial wind speed is set at $28.8 \mathrm{kmph}$ and after $2 \mathrm{sec}$ the wind speed is increased to $39.6 \mathrm{kmph}$ in the first pair of wind turbine over a period of $3 \mathrm{sec}$ and maintained at $39.6 \mathrm{kmph}$. Similarly the second pair of wind turbine speed was increased from $28.8 \mathrm{kmph}$ to $39.6 \mathrm{kmph}$ after $4 \mathrm{sec}$ over a period of $3 \mathrm{sec}$. At $\mathrm{t}=15 \mathrm{~s}$, a phase to phase fault is applied at the second set of wind turbine terminals terminals, causing the turbine to trip at $\mathrm{t}=$ 15.11 s. Simulations were carried on with the statcom and without statcom in the network. Figure 5 illustrates active and reactive power, generator speed, wind speed and pitch angle for each turbine during the first $6 \mathrm{sec}$ of operation.

The first graph in Fig. 5 shows the active power stabilizing to $3 \mathrm{Mw}$ in roughly $6 \mathrm{sec}$ as the wind speed increases from $8-11 \mathrm{~m} \mathrm{sec}^{-1}$. The second graph in Fig. 5 shows the reactive power increasing as the active power increases. The fourth graph show the wind speed increasing from 8-11 m $\mathrm{sec}^{-1}$ starting at $\mathrm{t}=2$ for the first wind turbine and the wind speed increasing for the second turbine at $t$ $=4 \mathrm{sec}$.

Figure 6 represents the performance of the wind farm when the second wind turbine fails due to a phase to phase fault at $t=15 \mathrm{sec}$. The first wind turbine continues its operation. 


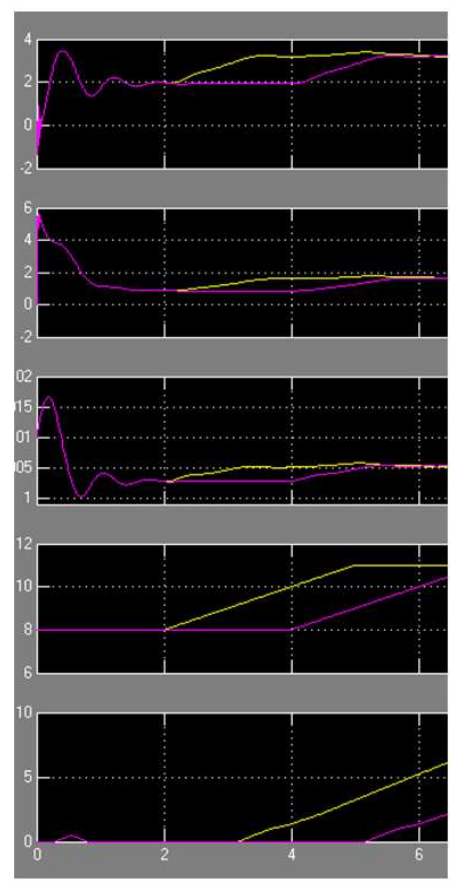

Fig. 5: Active power, Reactive power, Generator speed, Wind speed and pitch angle during the first six seconds of operation

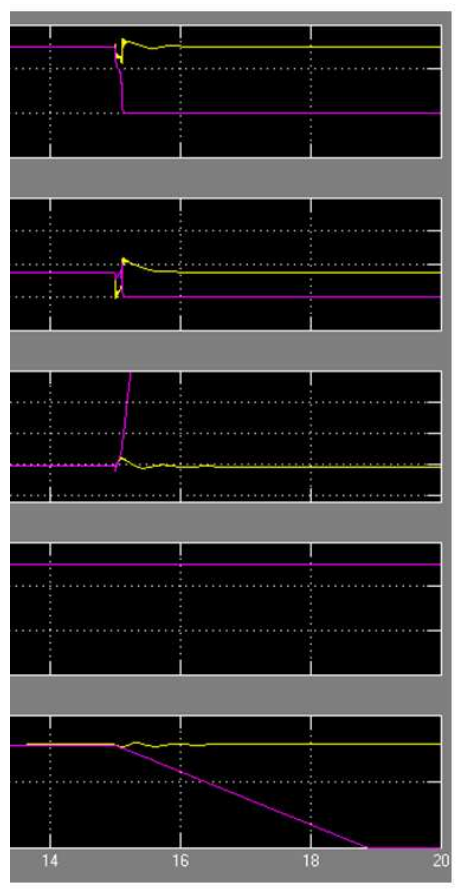

Fig. 6: Active power, reactive power, generator speed, wind speed and pitch angle during the phase to phase fault at $\mathrm{t}=15 \mathrm{~s}$

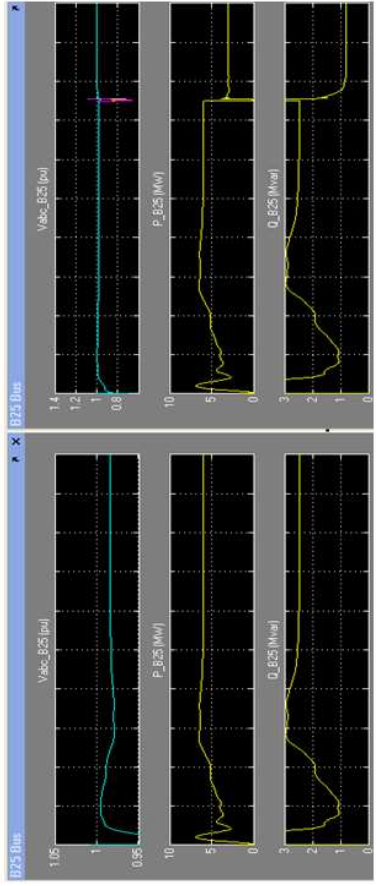

Fig. 7: Comparison of bus parameters with and without statcom

In the second experiment the statcom is disconnected from the system and the simulation is carried out as in the previous setup except that the phase to phase fault is eliminated. The comparative bus parameters are shown in Fig. 7. Due to the lack of reactive power the voltage at the bus falls to $0.98 \mathrm{pu}$.

\section{CONCLUSION}

In this study the power quality of a $6 \mathrm{MW}$ wind generation system using induction generators is investigated. It has been demonstrated that an additional active voltage support produced by a STATCOM can significantly improve the recovery of wind turbines from the fault due to faster restoration of the voltage, improving the stability of the induction generator. Since SVC's are cheaper than STATCOM for the same rating, it is desirable to study the effect of SVC in a wind energy system.

\section{REFERENCES}

Ahilan, T., K.P. Mohammed and S. Arumugham, 2009. A critical review of global wind power generation. Am. J. Applied Sci., 6: 204-213. DOI: 10.3844/ajassp.2009.204.213 
Al-Majed, S.I. and T. Fujigaki, 2010. Wind power generation: An overview. Proceedings of the International Symposium Modern Electric Power Systems (MEPS), Sept. 20-22, IEEE Xplore Press, Wroclaw, Poland, pp: 1-6.

Erkert, J., 2003. Harnessing the Wind: The Art of Teaching Modern Dance. 1st Edn., Human Kinetics, Champaign, IL., ISBN: 9780736044875 , pp: 211.

Hossain, M.J., H.R. Pota and V. Ugrinovskii, 2009. A Robust STATCOM control to augment LVRT capability of fixed speed wind turbines. Proceedings of teh 48th IEEE Conference on Decision and Control and 28th Chinese Control Conference, Dec. 15-18, IEEE Xplore Press, Shanghai, P.R. China, pp: 7843-7848. DOI: 10.1109/CDC.2009.5399579

Molinas, M., S. Vazquez, T. Takaku, J.M. Carrasco and R. Shimada et al., 2005. Improvement of transient stability margin in power systems with integrated wind generation using a STATCOM: An experimental verification. Proceedings of the International Conference on Future Power Systems, Nov. 18-18, IEEE Xplore Press, Amsterdam, $\quad$ pp: $\quad 6-6 . \quad$ DOI: 10.1109/FPS.2005.204256
Mittal, R., K.S. Sandhu and D.K. Jain, 2010. An overview of some important issues related to Wind Energy Conversion System (WECS). Int. J. Environ. Sci. Dev., 1: 351-363.

Qiao, W. and R.G. Harley, 2008. Grid connection requirements and solutions for DFIG wind turbines. Proceedings of the IEEE Energy 2030 Conference, Nov. 17-18, IEEE Xplore Press, Atlanta, GA., pp: 1-8. DOI: 10.1109/ENERGY.2008.4781068

Ramakumar, R., J.J. Bzura, J. Eyer, J. Gutierrez-Vera and T.E. Hoff et al., 1999. Renewable technologies and distribution system. IEEE Power Eng. Rev., 19: 5-14. DOI: 10.1109/MPER.1999.799631

Srinivas, V. and M.L.S. Devakumar, 2010. Optimization of power factor and energy management in wind energy station. Int. J. Comput. Commun. Inform. Syst., 2: 233-240.

Toledo, P.F.D. and H. Xie, 2005. WIND farm in weak grids compensated with STATCOM. KTH, Kungl Tekniska Högskolan, EME department, Teknikringen 33-35, Stockholm, Sweden. 